\title{
THE STUDY OF DIFFERENT MECHANICAL SYSTEMS AND SUB SYSTEMS OF JAIPUR METRO RAIL
}

\author{
Karamjit Singh \\ Department of Testing \\ Bharat Earth Movers Limited, Bangalore
}

\begin{abstract}
A Metro may be a Railway Network that's designed to hold large numbers of passengers for brief distances using rail cars. It's characterized by an entire segregation from pedestrians and roads (usually underground). It's a system utilized in extremely large and populous cities. Efforts are made during this study on a number of the essential technical systems of a metro rail. The study performed at the Rolling Stock department of Jaipur Metro Rail Corporations. Study was performed on the major mechanical systems of Metro rail system like bogie, Coupling System, Braking systems, Door System and Air conditioning System.
\end{abstract}

\section{Key Words: Metro System, Metro Brake, HVAC System,} Metro Door System

\section{INTRODUCTION}

Jaipur Metro is a mass rapid transit system within the city of and the network has been expanding rapidly across the region. For Smooth running of Metro System proper care should be required. The maintenance center deal with repair/maintenance activities pertaining to the rolling stock. Such Department keep a regular check of coaches from time to time (maintenance Check) and carry out necessary changes to maintain the quality and safety of the metro rail system. Rolling stock Department deal with all the System of Metro Rail like Mechanical System, Pneumatic, Braking, and Air-conditioning systems. Assembly of coaches is also the responsibility of rolling stock Department.

\section{POSITION OF COACHES}

In the metro rail there are two types of train coaches namely the Driver-Trailer (DT) car and Motor (M) car. One DT and one $\mathrm{M}$ car serve as one unit. $\mathrm{M}$ car consists of the main motor for the purpose of transmission. Whereas the DT car consists of the pantograph assembly for power supply purposes which is connected to the $25 \mathrm{kV}$ over-head extension. Hence, Separately the DT and M car cannot be used. Result of this, even number of coaches only (4, 6 and now 8 coaches are common) used in the metro rail System.

\author{
Pankaj Saraswat \\ Department of Testing \\ Bharat Earth Movers Limited, Bangalore
}

Also, the DT car at the ends of the metro rail is essential. Because train operator's cabin in the DT car. In four-coach metro train System general arrangement of coaches is shown below.

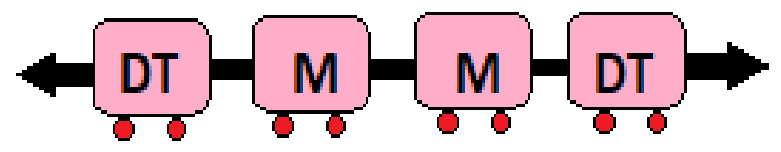

Fig. 1. Four coach train System

\section{MAIN MECHANICAL SYSTEM}

Metro Rail system incorporate the following Mechanical systems and Sub-systems:

1. Bogie

2. Coupler

3. Brake System

4. Door System

5. HVAC System

\subsection{BOGIE}

The main functions of the bogie and suspension are to support the vehicle and passenger load, to transfer the traction force and braking forces and to maintain good ride quality and stability.

The bogies are of bolster-less type incorporating a steel-and-rubber primary suspension system, and a secondary pneumatic suspension system, and with axle bearings mounted outboard of the wheels. The bogies are of 2 types: motor bogie and the trailer bogie, which have similar bogie frame configuration except the motor brackets and the driving gear brackets in the motor bogie.

The bogie is equipped with the necessary equipment for safe, comfortable and efficient running of the vehicle and designed to be easily accessible to the parts of the bogie. The bogie is mainly composed of as follows. 


\section{International Journal of Engineering Applied Sciences and Technology, 2020 \\ Vol. 5, Issue 1, ISSN No. 2455-2143, Pages 252-255 \\ Published Online May 2020 in IJEAST (http://www.ijeast.com)}

- Fabricated bogie frame.

- Wheel set.

- Suspension system including the anti-roll bar.

- Center pivot device

- Mechanical driving system and braking system.

- Auxiliary equipment's on Journal box.

\subsection{COUPLER}

There are three differing types of couplings utilized in between different coaches of a metro train. These are:-

1. Front Automatic Coupling (FAC)

2.Semi- permanent Coupling (SPC)

3.Intermediate Automatic Coupling (IAC)

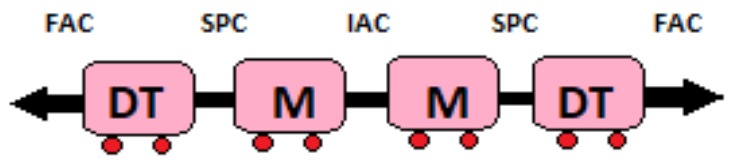

Fig. 2. Types of couplings between different coaches

\subsubsection{Front Automatic Coupling (FAC)}

This coupling is employed at both ends of the metro train i.e., ahead of the DT car. The FAC is automatic operational and hence is extremely useful just in case of rescue operations. During res- cue operations, the FAC of the rescue Fig. 1. Four coach train System4train couples with the FAC of the train to be rescued automatically on impact. No manual effort on a part of the train operator is required to cou ple the 2.trains.

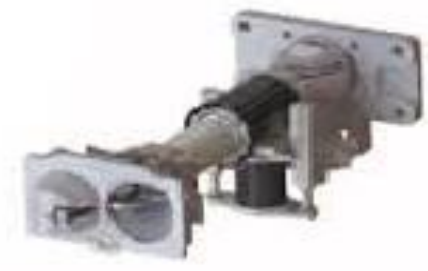

Fig. 2. Front Automatic Coupler

\subsubsection{Semi- permanent Coupling (SPC)}

This coupling is incorporated between the DT and $M$ cars. Since the DT and $M$ cars function one unit, they're not usually required to be separated. Hence, a semi- permanent coupling is employed between the DT.and.M.car.

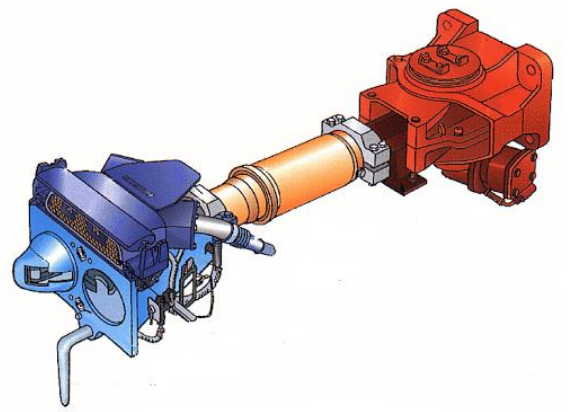

Fig. 3. Semi-permanent Coupler

\subsubsection{Intermediate Automatic Coupling (IAC)} This coupling is employed between two $M$ cars so as to facilitate easy engagement of coaches especially when the amount of coaches has got to be increased.

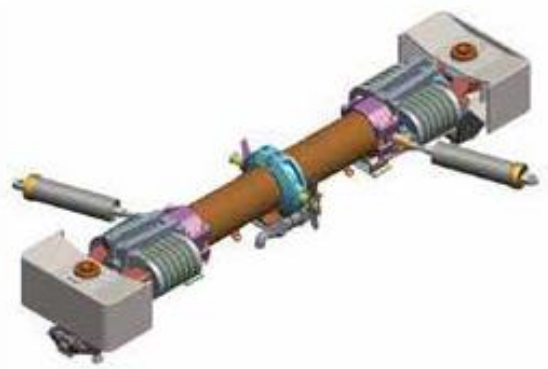

Fig. 4. Intermediate Automatic Coupler

\subsection{BRAKES SYSTEM}

Brake System works on the principle of application of brakes using the force exerted by compressed air. There are five differing types of brakes within the metro rail system supported their purpose of operation.

$\begin{array}{ll}\text { 1. Service } & \text { brakes } \\ \text { 2. Emergency } & \text { brakes } \\ \text { 3. Parking } & \text { brakes } \\ \text { 4. Holding } & \text { brakes }\end{array}$

3.3.1.Service Brakes: These brakes constitute the most braking system of a metro rail. They operate during normal running conditions and also are equipped with a regenerative braking system. The Kinetic Energy lost on account of application of brakes is converted into useful electricity and either stored within the battery system or supplied back to the overhead extension (OHE) so as to be employed by other rails on the network.

\subsubsection{Emergency Brakes: These brakes}




\section{International Journal of Engineering Applied Sciences and Technology, 2020 Vol. 5, Issue 1, ISSN No. 2455-2143, Pages 252-255 \\ Published Online May 2020 in IJEAST (http://www.ijeast.com)}

are utilized in case of emergency. It are often directly applied by the train operator. Besides, albeit some condition isn't fulfilled during operation and located potentially dangerous, a sign is shipped to the Brake Electronic Control Unit (BECU) and subsequently to the Brake Control Unit (BCU) which further changes the signal into a pneumatic signal to use brakes.

3.3.3.Parking Brakes: These brakes are used when the train is parked during a depot. Each metro car features a set of 4 parking brakes, with two brakes installed on one bogie. They are installed on the DT car and may be applied either manually or automatically when the reservoir pressure is low.

3.3.4.Holding Brakes: These brakes are wont to prevent the train from rolling back on a rising gradient. They are particularly useful when the train is standing on a station or during a depot. These brakes operate a pressure which is seventy percent of the service brake pressure.

The major component of Brake system are:

1. Brake Electronic Unit (BECU)

2. Brake Control Unit (BCU)

\section{Brake Electronic Control Unit. (BECU)} This is the most control unit that's liable for receiving signals from the train operator to use brakes. It also keeps a check on the load exerted on the air suspension and develops electrical signals accordingly. When the train operator has got to apply the brakes, he gives the signal to BECU. Accordingly, the BECU gives command to use the electrical regenerative braking. However, if the braking effort isn't sufficient, then command for pneumatic braking is generated. The braking provided is load corrected, i.e., if the load is more, then more pressure are going to be applied. During braking, wheel sliding is prevented with the assistance of an anti- skid valve. This valve is additionally controlled through BECU.

Brake Control Unit (BCU) This unit is liable for receiving electrical signals from BECU and converting these signals into pneumatic signals. The BCU consists of various valves. Consistent with the pneumatic signal generated with the $\mathrm{BCU}$, a corresponding pressure is generated to use brakes.

\subsection{DOOR SYSTEM}

There are differing types of doors installed within the metro rail to facilitate different functions. These are:-

1. Cabin door

2. Emergency door

3. Partition door

4. Passenger door

\subsubsection{Cabin door:}

This door is installed on each side of the DT car. It's used only by the train operator to maneuver into and out of the cabin. It's operated manually.

\subsubsection{Emergency door:}

This door is installed on both ends of the metro train. The access to the present door is thru the train opera- tor's cabin. It's operated manually with the assistance of a lever. This door is employed as a final resort when all the attempts to open the passenger body side doors fail.

\subsubsection{Partition door:}

This door is found between the driver's cabin and therefore the saloon of the DT car.

\subsubsection{Passenger door:}

This door is installed on all sides of the DT or M car to facilitate the movement of passengers into and out of the train. The opening and shutting of this door is facilitated through electronic means.

\section{Passenger door Working Mechanism}

The DCU processes the signal received from the train operator to open or close the door. It accordingly sends an electrical signal to the static magnet D.C. motor which is connected to the spindle shaft with the assistance of a Drive gear. As the motor operates, it rotates the spindle shaft within the clockwise or anti-clockwise direction as per the signal received from the DCU. The movement of the spindle shaft is transferred to the drive brackets through the spindle nuts. The drive brackets then translate on the spindle shaft within the opposite directions, thus opening or closing the door within the process.

\subsection{HVAC SYSTEM (HEATING, VENTILATING, AND.AIR.CONDITIONING)}

HVAC System is meant to satisfy the demanding climate also because the high passenger density observed in Indian metropolitan areas. so 


\section{International Journal of Engineering Applied Sciences and Technology, 2020 \\ Vol. 5, Issue 1, ISSN No. 2455-2143, Pages 252-255 \\ Published Online May 2020 in IJEAST (http://www.ijeast.com)}

as to make sure a suitable air quality on-board the new commuter cars operated by the Jaipur Metro rail Corporation M/S Sidwal has designed a forced ventilation to provide large amounts of ambient fresh air to the passenger area.

\section{Operation Mode of HVAC System:}

The major operating mode of HVAC System are as follow:

1. Normal Operating Mode

2. Emergency Operating Mode

3. Smoke Mode

\subsubsection{Normal Operating Mode}

Normal Operating Mode is an Automatic operation mode in which HVAC unit provides required cooling and ventilation automatically by various sub modes.

\subsubsection{Emergency Operating Mode}

Emergency Operating Mode will activate when $25 \mathrm{kv}$ power supply is not available. HVAC system will supply only fresh air in this mode.

\subsubsection{Smoke Mode}

Smoke mode is activate when more smoke will found in environment outside the Train .In this mode system provides full recirculation of return air within the saloon and shuts off the fresh air intake from environment.

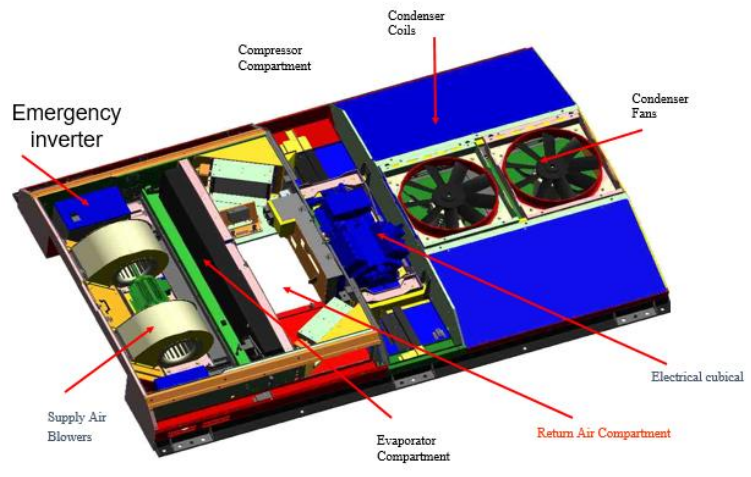

Fig. 3. Different Parts of HVAC System.

\section{CONCLUSION}

The study performed at the Rolling Stock department of Jaipur Metro Rail Corporations. Study was performed on the major mechanical systems of Metro rail system like bogie, Coupling System, Braking systems, Door System and Air conditioning System. Trains are maintained at Mansarovar Deport for Pink Line. These rolling stocks are said to be indigenous and are manufactured by BEML at its factory in Bangalore. The trains are four-car consists with a capacity of 1506 commuters per train, accommodating 50 seated and 292 standing passengers in each coach. These trains have automated doors, power supply connections charge mobiles and laptops, HVAC System for humidity control, Disc brakes for proper braking and can be capable of maintaining a mean speed of $32 \mathrm{~km} / \mathrm{h}(20$ $\mathrm{mph})$ over a distance of $1.1 \mathrm{~km}(0.68 \mathrm{mi})$.

\section{REFERENCES}

1. Bhagyalakshmi R, Dr. James K C" Study of Energy Utilization in a Metro Rail Limited Company" IJEDR | Volume 5, Issue 4 | ISSN: 2321-9939 2017

2. Prateek Malhotra\#, Ajay K. Duggal," Metro Rail Transit System In Various Indian Cities - A Preliminary Study" International Journal of Engineering Science Invention Research \& Development; Vol. III, Issue I, July 2016

3. Karan Arora "Study of Various Technical Systems Incorporated in a Metro Rail System" International Journal of Scientific \& Engineering Research, Volume 5, Issue 5, May-2014 377

4. See Yenn Chong, Jung-Ryul Lee and Hye-Jin Shin, "A review of health and operation monitoring technologies for trains", Smart Structures and Systems, Vol. 6, No. 9 (2010) 1079. -1105 1079

5. Rolling Stock Department, Jaipur Metro Rail Corporation, Jaipur

6. https://en.wikipedia.org/wiki/Jaipur_Metro 